\title{
LINKING ORGANIZATIONAL CHANGE, COORDINATION MECHANISMS AND INCENTIVE SYSTEMS IN DIFFERENT INDUSTRIES
}

\author{
José Ignacio Galán, jigalan@usal.es, Universidad de Salamanca \\ María José Sánchez Bueno, mjsanchez@usal.es, Universidad de Salamanca \\ José Ángel Zúñiga Vicente, joseangel.zuniga@urjc.es, Universidad Rey Juan Carlos
}

\begin{abstract}
This is an exploratoy study which provides preliminary empirical evidence on the relationship between coordination mechanisms and the evolution of organizational forms and, mainly, the role that incentive systems can play as a potential determinant of the organizational change process. The empirical setting consists of two large Spanish firms belonging to different industries. Our findings reveal that the incorporation of networking elements in new forms of organization requires the increased weight of incentive systems linked to cultural, social and psychological aspects that extend beyond the so-called contractual approach. Likewise, our study reveals that during the process of organizational change companies would have to introduce incentive systems that allow for the co-existence of exploration and exploitation actions. Nonetheless, it can be observed how in more traditional settings, they should place greater importance on incentive systems aimed at upholding exploitation actions, whereas in more innovative environments greater significance should be attributed to incentive systems designed to favor actions linked to exploration.
\end{abstract}

Keywords: new organizational forms, coordination mechanisms, incentive systems, exploration and exploitation, longitudinal analysis 


\section{INTRODUCTION}

Over the past twenty years, the world has undergone major change in the face of technological transformation and growing globalization. Accordingly, rising rates of instability and turmoil mean that companies have had to adapt their organizational structures to respond to these changes. Therefore, new patterns of organizational behavior may have emerged in recent years. As a direct result of this current preoccupation with new organizational forms, a proliferation of articles has appeared that adopt varying perspectives [For instance, federal structure (Handy, 1992), modular organizational forms (Sanchez \& Mahoney 1996), virtual organizations (Ahuja \& Carley 1999) or the appearance of the cellular form (Miles et al., 1997)].

In addition, a significant body of literature focuses particularly on exploring the nature of this evolution in organizational forms and describing the essential internal characteristics of new organizational forms such as the internal network or N-Form (Hedlund 1994; Pettigrew \& Fenton 2000; Child \& McGrath 2001; Pettigrew et al., 2001). However, this field of research is still in its infancy and, therefore, remains underspecified and nebulous (Pettigrew \& Fenton, 2000). In this sense, it is necessary to further knowledge on the evolution of traditional organizational forms and on the distinctive characteristics of new ones. The way in which organizational forms evolve from traditional forms to new ones in terms of the evolution of the coordination mechanisms is an important gap in previous literature that this research sets out to bridge. One of this paper's initial objectives, therefore, consists in studying how coordination mechanisms evolve from more traditional forms into more modern organizational forms, until patterns are detected that define these new organizational forms. Accordingly, the initial valued added of the present paper with regard to prior literature consists in adopting a systematic approach to describing the evolutionary process of forms in terms of coordination mechanisms in order to develop new insights from a unique, previously unexplored context.

Furthermore, once identification has been made of evolutionary processes involving organizational forms, the way in which incentive systems influence such features in organizational change is another gap in existing literature that this research aims to fill. The study on how incentive systems affect organizational structures is an area that has scarcely been addressed by prior literature. We firmly believe that the reward system can represent a particularly powerful tool for influencing organizational change. The present paper thus presents a fresh approach based on the work of James March (1991) as to how incentive systems are going to have a bearing on organizational transformation processes.

Based on the above notions, the first research question posed by this paper is: how does the coordination mechanism evolve from traditional forms of organization to new forms of organization? Once this first question has been explored, the second research question that we address in this paper is: how is organizational transformation affected by incentive systems?

The research setting chosen for exploring these research questions involves two large Spanish companies over an 11-year period (from 1991 to 2001). Both companies are domestically-owned firms and are amongst the country's largest industrial companies, and are clear examples of success in recent years. Thus, both companies are characterized by sharing a similar institutional context, although they do not share the same technological context. The Zeltia Group belongs to a highly technology-intensive sector in the new economy, whereas the Cortefiel Group belongs to a traditional, highly labor-intensive industry. This may shed light on evolutionary patterns in terms of the turbulence of the environment as well as the impacts of incentive systems on these evolutionary patterns linked to exploration and exploitation activities. 
As noted by many researchers, most empirical studies hitherto carried out on this question, with a few limited and noteworthy exceptions, have serious shortcomings. They are basically static, transversal, and noncontextual in character (Garud \& Van de Ven 2001; Pettigrew et al., 2001; Pettigrew 1992). This justifies the recent, growing emphasis whereby empirical research in this field needs to be much more realistic in order to provide useful advice and/or ideas to organization managers and practitioners in general, as well as to be academically rigorous. Accordingly, we use process research methodology and we concentrate on the phenomenon in a new real context: the context of Spanish firms in a recent time period. The main value added of the work, therefore, with regard to prior literature is the scant knowledge and novelty presented by the research issues, on the one hand, and the unique, unexplored setting, on the other.

The paper is organized as follows. In the second section, we present the theoretical background to new organizational forms based on several issues associated with coordination mechanisms. In the third section, we present the role of incentive schemes in this organizational change. In the fourth section, the methodology used in this work is addressed. We then go on to analyze the empirical evidence by means of two Spanish firms. Finally, our more relevant findings and conclusions are presented.

\section{LINKING COORDINATION MECHANISMS AND ORGANIZATIONAL FORMS}

Drawing on the recent conceptual framework of Saloner et al., (2001), we consider three coordination issues: (a) level of specialization and integration of a firm's human resources; (b) decision-making processes: centralization and decentralization; and (c) information flows. Based on these, we seek to underscore the more pertinent distinctive characteristics of the traditional forms (M-form and H-form) and of new forms (internal network or N-form).

Regarding the first issue, there is a clear difference between the traditional forms ( $\mathrm{M}$-form and H-form) and the $\mathrm{N}$-form mode for organizing and integrating human resources in the firm. The M-form consists of quasiautonomous or highly independent divisions (organized along functional lines), which are characterized by a very high level of specialization. In fact, it has been frequently considered in the literature as a set of organizational structures with specialized U-form (Williamson 1975). According to Williamson, the main advantage of this structure is the economy of managerial attention provided by decomposition and specialization. The H-form shows similar features in this aspect, since this structure is a decentralized M-form (Williamson \& Bhargava 1972). By contrast, the $\mathrm{N}$-form consists of a large number of interdependent temporary subunits characterized by a lower level of specialization. These subunits are composed of employees who continuously rotate around these units. In this structure, there are no clearly defined roles amongst the firm's different members (Hedlund 1994).

As regards the second issue, a clear initial difference can be seen between both traditional forms of organization. One of the more important features of the M-form is the delegation of authority from the general office toward each individual division. In particular, there is a high level of centralization in the M-form regarding strategic decision-making and a high level of decentralization concerning operating decisions. Division managers control, monitor and set specific and concrete objectives on routine activities, whereas the general office managers control, monitor and set specific and concrete objectives on strategic activities that include planning, control, assessment and allocation of resources to each individual division. Consequently, there is considerable competition between the different divisions to obtain resources from the general office. Likewise, 
the staff in this organization form provides professional advice to the general office in order to monitor the organizational behavior of each individual division (Williamson 1975). By contrast, although the H-form is decentralized operationally, strategic control of the center is often only partial or unsystematic. This organizational structure lacks the requisite internal control apparatus of the M-form and cash flows are not exposed to internal competition but returned to source divisions (Williamson \& Bhargava 1972; Williamson 1975). On the other hand and, in contrast to hierarchy, the general office in the N-form is not so important, since its fundamental role basically lies in promoting relationships between the different organizational subunits that make up the network. In other words, the role of general office leaders is limited to providing general guidance and managing conflict. Thus, the basic organizational level in this structure is not the top management but rather the intermediate managers and employees (Hedlund 1994; Grant 2001; Teece 2001).

Finally, in reference to information flows, it is usually argued that information is an essential factor upon which coordination hinges. Milgrom and Roberts (1992) suggest that a key problem in the securing of effective coordination and adaptation is that precise information for delimiting the best possible use of organizational resources and proper innovations is not within everyone's reach. While in some organizations there is direct access to critical information flows on their activities, in many others the information systems provide specific information channels for very few employees. Moreover, the way of assigning decision rights must be clearly in accordance with the design of information flows (Saloner et al., 2001). Since the M-form is characterized by hierarchical control, information will run vertically rather than horizontally from top to bottom, as that is where all relevant knowledge is located. However, the $\mathrm{N}$-form is characterized by an atmosphere of closer collaboration, confidence and integration between the different groups of organizational members, so information runs horizontally rather than vertically (Barlett \& Ghoshal 1993; Hedlund 1994; Van Wijk \& Van den Bosch 2000). Midway between these two structures is the H-form. In this type of organizational form, hierarchical control is not as strong as in the M-form, but horizontal cooperation is weaker than in the N-form. A summary of the coordination problems of the different organizational forms is presented in Table 1.

Table 1: coordination mechanisms and organizational forms

\begin{tabular}{l|l|l|l}
\hline \multirow{2}{*}{$\begin{array}{c}\text { Coordination } \\
\text { Problems }\end{array}$} & \multicolumn{1}{|c}{ Organizational Forms } \\
\cline { 2 - 4 } $\begin{array}{l}\text { Specialization of } \\
\text { human resources }\end{array}$ & $\begin{array}{l}\text { High level of } \\
\text { specialization }\end{array}$ & $\begin{array}{l}\text { Low rotation of employees } \\
\text { across the units }\end{array}$ & $\begin{array}{l}\text { Low specialization and there are no } \\
\text { clearly defined roles amongst the } \\
\text { firm's members }\end{array}$ \\
\hline $\begin{array}{l}\text { Decision-making } \\
\text { process }\end{array}$ & $\begin{array}{l}\text { Centralized strategically } \\
\text { and decentralized } \\
\text { operationally }\end{array}$ & $\begin{array}{l}\text { High operational } \\
\text { decentralization and low } \\
\text { strategic centralization }\end{array}$ & $\begin{array}{l}\text { Decentralization. Business unit } \\
\text { autonomy }\end{array}$ \\
\hline Information flows & $\begin{array}{l}\text { Hierarchical control: top- } \\
\text { down strategic control } \\
\text { over the corporate whole. } \\
\text { Vertical knowledge } \\
\text { flows. }\end{array}$ & $\begin{array}{l}\text { Strategic control of the } \\
\text { center is often partial or } \\
\text { unsystematic. Some degree } \\
\text { of horizontal collaboration. }\end{array}$ & $\begin{array}{l}\text { Horizontal cooperation. Horizontal } \\
\text { processes of knowledge emerge } \\
\text { through inter-functional work teams. } \\
\text { This task forces the sharing of } \\
\text { experience between decentralized } \\
\text { units. }\end{array}$ \\
\hline
\end{tabular}

SOURCE: the authors. 
In addition, a notion has recently been propounded (Pettigrew \& Fenton, 2000) regarding the co-existence between the attributes of traditional forms and the new forms. Based on the idea of co-existence, discovery has recently been made of new organizational forms referred to as the 'multidivisional network' form, which combines elements of the multidivisional structure with the network form (Whittington \& Mayer, 1997, 2000) and 'holding network' which combines elements of the holding structure with networking elements (Galan et al., 2005).

\section{INCENTIVE SYSTEMS AS A DRIVING-FORCE FOR ORGANIZATIONAL CHANGE}

Following the conceptual studies of Milgrom and Roberts (1992), Saloner et al., (2001) and Roberts (2004), we are interested in stressing the possible influence of the incentive systems used by firms in organizational change and, especially, within earlier and newer organizational forms. As is widely known, one of the more important problems frequently facing a firm lies in encouraging its different employees to pursue objectives or take actions that are consistent with the achievement of the firm's goals. Most of the firm's employees have different concerns and may be willing to pursue their own objectives at the expense of the firm's. These divergent objectives give rise to the so-called incentive problem (e.g. Baron \& Kreps 1999; Gibbons 1998; Lazear 1998; and Zajac \& Westphal 2002). The problem of motivating people in organizations stems from the fact that their own self -interest may not automatically lead them to act in the way that the organization would want them to. This divergence of interests arises because, generally-speaking, the individual members of an organization do not bear all the costs and enjoy all the benefits of the actions they take and of the decisions they make within the organization. In general, motivation or incentive problems arise when an individual's organizational decisions and actions affect others in ways that the individual does not fully consider-when there are externalities (Roberts, 2004: 118-119).

The source of this typical problem arises from the principal-agent relationship, which is traditionally examined from the agency theory. This problem can be satisfactorily resolved by using an appropriate incentive system for all the firm's employees. When the firm's objective is to achieve a particular type of organizational change, the employment of an appropriate incentive mechanism may be the key link to set that organizational change process in motion. If a firm uses a proper incentive system, then it seems reasonable to infer that the objectives of all its employees will be in tune with those of the firm, so that the firm will strive to the utmost to achieve its own objective; in this case, the change in its organizational structure. Nonetheless, if different groups of employees notice that the incentive system is not the most appropriate one for them, then their dissatisfaction and frustration will be present as they go about their different jobs in the firm. They will be very scarcely motivated and, therefore, their objectives may diverge completely from the firm's own objectives and, hence, the process of changing the organizational structure will falter.

In addition, applying the thinking of Saloner et al., (2001) and Roberts (2004), we postulate that the incentive system in a broad sense will go beyond the traditional concept of the agency theory. Aspects such as people, architecture, culture, process and routines will also have a bearing on the appropriate influences that underscore organizational change beyond merely contractual relationships. If an organization is to use its incentive systems to generate value, the elements containing distributed incentive systems must somehow cohere. Coherence evolves as people in organizations choose specific metrics and implement procedures to use 
and combine incentive systems from different elements to achieve value according to these metrics. Accordingly, in keeping with the influential work of James March (1991), we consider that exploration actions are going to require a specific type of incentive systems, whereas exploration actions are going to require another kind of incentive systems in the transition process towards new forms of organization. A chart summarizing the literature on the distinctive traits of exploration and exploitation actions is presented in Table 2.

Table 2: certain distinctive characteristics of exploitation and exploration models

\begin{tabular}{|c|c|}
\hline Model & Exploration Model \\
\hline 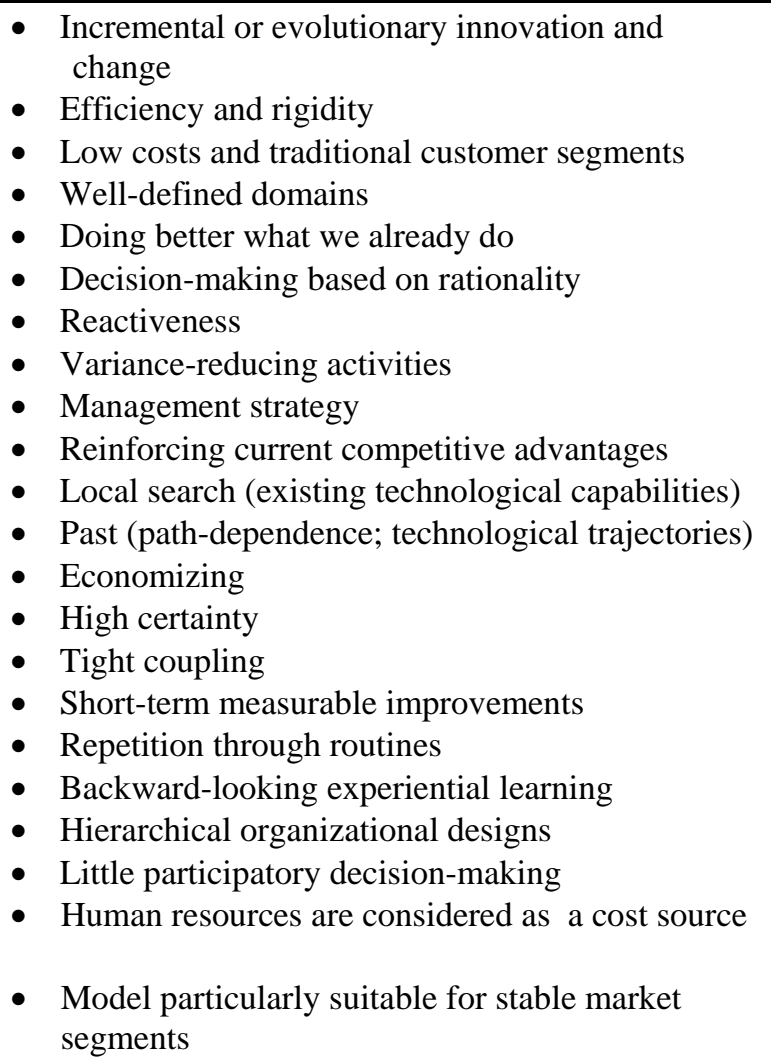 & $\begin{array}{l}\text { - Radical or revolutionary innovation and change } \\
\text { - Innovation and flexibility } \\
\text { - Differentiation and new customer segments } \\
\text { - Changing domains } \\
\text { - Novel ways of doing things } \\
\text { - Decision-making based on creativity } \\
\text { - Proactiveness } \\
\text { - Variance-increasing activities } \\
\text { - Entrepreneurial strategy } \\
\text { - Developing new sources of competitive } \\
\text { - } \text { advantage } \\
\text { - } \text { Histant search for new capabilities } \\
\text { - Strategizing and organizing } \\
\text { - High uncertainty } \\
\text { - Loose coupling } \\
\text { - Long-term improvements difficult to measure } \\
\text { - Creation of new routines } \\
\text { - Forward-looking cognitive models } \\
\text { - Horizontal organizational designs } \\
\text { - Highly participatory decision-making } \\
\text { - Human resources practices are essential for } \\
\text { - achieving a sustainable competitive advantage } \\
\text { - Model particularly suitable for highly unstable } \\
\text { and changing market segments }\end{array}$ \\
\hline
\end{tabular}

SOURCE: the authors.

An organizing mode is a statutory orientation that facilitates a particular way of using incentive systems. "An organizing mode highlights what is significant for an organization, mobilizes energy to facilitate what is significant, and enables sanctions to maintain what is significant” (Dunbar \& Garud, 2005: 204).

As innovation is the central aspect of Zeltia's corporate identity, the Zeltia organizing mode for managing incentive systems should consistently support innovation. Thus, according to James March's approach, it is to be expected that the company Zeltia, which is in a technology-intensive sector, will adopt a system of incentives linked to the organizational mode that emphasizes exploration. On the other hand, the Cortefiel Group belongs to a sector of traditional activity in which there are well-established procedures and, in this case, it is to be expected that the company will adopt incentive systems linked to the organizational mode that stresses exploitation. 


\section{METHODS}

\subsection{Research design}

The research design of this study is based on two longitudinal case studies. We used this type of methodology for the four following fundamental reasons (Eisenhardt, 1989; Pettigrew, 1990; Yin, 1994; Galan, et. al. 2005). Firstly, this method focuses on explaining and understanding the dynamics present within single settings. In others words, it enables researchers to examine in-depth phenomena of organizations within their real context. Secondly, longitudinal case studies combine different data collection methods which permit researchers to gain a better view of every organizational phenomenon over time. Thirdly, this method can be used to provide description and to generate theory. Lastly, we were in search of temporal interconnections of events. We recognize that given that we do not know very much about the issues of interest in this line of research, our intention is to conduct inductive case research and, thus, in some way to provide new evidence in order to give an insight into what is occurring.

On the other hand, not only do we want to bring time into the analysis (longitudinal aspect) but we also want to offer a comparative perspective. For this reason, we have selected two large Spanish industrial firms, which belong to two different environments-the Zeltia Group carries out its core activities within highly innovative sectors, the chemical and biotechnology industries, while the Cortefiel Group is included within a more traditional industry, the textile sector. In addition, these companies have a different basic approach to organization, and they have been engaged in ongoing processes of structural realignments over time as a direct result of continuous and far-reaching changes in their environmental conditions.

Finally, we are particularly interested in providing new exploratory evidence on the issues investigated within an institutional context and a timeframe that has hitherto been scarcely analyzed in organization literature. Therefore, there is still a relative lack of empirical studies with new evidence for several years that have witnessed fundamental environmental transformations in every economy worldwide, in general, and in Spain, in particular.

\subsection{Data Collection}

Our research uses a triangulation methodology and combines documentary sources with interviews. Documentary sources included annual reports, company histories, teaching cases, business directories, press reports and information available on the internet. However, the most relevant information was collected through two questionnaires and semi-structured individual interviews specifically designed for this research. Informants in both cases included each general manager, several functional managers and lower-level managers. Interviews were conducted during site visits to each firm. Informants were briefed beforehand regarding the objective of our research, and the interviews were transcribed.

In order to ascertain the fundamental internal characteristics of organizational modes associated with the evolution of coordination problems, we examined and collected information on the following issues: level of centralization-decentralization in the decision-making process, nature of information flows, level of importance of modularity and teams and work groups in each firm in the timeframe under study. Finally, we analyzed the role associated with incentive mechanisms by collecting information related to the different types of rewards and motivation employed by each company in the same timeframe. 


\section{EMPIRICAL EVIDENCE}

The examination of both companies follows the same framework. We begin with a brief history of each company from its incorporation. We then provide new exploratory evidence on the evolution of several internal characteristics closely coupled to the possible emergence of new organizational forms in terms of their coordination problems and, finally, we provide insight as to how incentive systems affect the change in organizational structure.

\subsection{The Case of the Zeltia Group: brief history}

This company was incorporated in 1939, the year in which the Spanish Civil War ended and War World II began. The Zeltia Group is a large family-owned Spanish group whose main business lies in the consumer chemical and biotechnology sectors. The group’s leading firms in the consumer chemical sector, Zelnova and Xylazel, each maintain their leading position in the domestic market. Zelnova runs a household and industrial insecticide and air-freshener business and is a leader in insecticides for home use. Xylazel runs a decorative and protective wood products business, and is a leader in products for wood protection. With regard to the biotechnology business, the Zeltia Group has recorded its foremost success in the current decade through two companies, Pharma Mar and Pharma Gen. Pharma Mar was set up for the development of marine-based pharmaceuticals for medical applications, especially those biologically active in the antitumoral field. Pharma Gen carries out activities such as paternity tests, forensic analyses, and the manufacture of diagnostic kits for a variety of diseases, all based on DNA analysis technology. Theses four companies and Inmunal (auto-vaccines) and PROMAX (wood recovery treatment and conservation services) make up this important group.

Moreover, a crucial feature of the Zeltia Group is its ongoing and dedicated commitment to innovation. This commitment was apparent over the entire timeframe under study, and it was particularly acute for the last three years (from 1999 to 2001). Specifically, in these last three years, the average R\&D expenditure as a percentage of net sales rose from $13.39 \%$ in 1999 to $20.10 \%$ in 2000 and to $32.10 \%$ in the final year.

\subsection{Organizational change in the Zeltia Group from 1991 to 2001}

The organizational form used by the Zeltia Group over the 11-year period under study was the holding structure (H-form). This group has a small general office with a staff of about 15-20 people. All subsidiary firms (Zelnova, Xylazel, Pharma Mar, Pharma Gen, Inmunal, and PROMAX) are highly independent and are structured as functional forms with their own departments for manufacturing, sales and finance. The central office has a minimum role and there is no strategic control. The different units only depend on the headquarters in a few issues related to the most important decisions. The divisional managers have considerable responsibility; they can submit suggestions regarding new business and other similar types of strategic decisions.

However, an important difference can be noted between the organizational structure adopted at the beginning and the end of this timeframe, since some characteristics of the holding structure are actually starting to coexist alongside features of the $\mathrm{N}$-form. The main organizational characteristic that enables us to talk of the emergence of the $\mathrm{N}$-form is the increasing importance given to horizontal information flows.

The Zeltia Group is included in the R\&D intensive sectors and, therefore, it allocates considerable resources to innovation. In fact, this group maintains extremely important partnership agreements with several of the most prestigious academic institutions and hospitals all over the world in different research projects, in areas 
such as marine biology and microbiology, natural marine products, synthesis and elucidation of chemical structures, pharmacology, drug toxicology and metabolism, studies on action mechanisms and clinical and preclinical experiments/tests. As a result of the important technological changes of recent years, the Zeltia Group has had to promote trust and collaboration amongst the different members of the organization in order to achieve its goals. For this reason, it has formed experienced work teams made up of employees from different organizational departments. There are many examples of work teams in different activities, such as marine operations, clinical and preclinical research, and the chemistry of natural products. Therefore, whereas in previous years knowledge was fundamentally transferred to and applied at higher levels, now a great deal of knowledge is retained at unit level and is transferred and integrated amongst organizational units. In other words, in 2001 there was important lateral communication or horizontal cooperation.

Accordingly, the arguments put forward regarding coordination mechanisms are consistent with the results of Galan et al., (2005), which point to the appearance of the 'holding network' as a new organizational mode in which elements of the traditional mode (H-form) coexist with the new mode ( $\mathrm{N}$-form). What role have incentive systems played in this process of organizational transformation?

\subsection{The Role of Incentive Systems in the Organizational Change Process in Zeltia}

In the Zeltia Group, the design of an appropriate incentive system is considered to be one of the main factors contributing to the achievement of a successful organization. The incentives system implemented by the Zeltia Group throughout the period 1991-2001 presents features linked to the exploration model presented in Table 2. The various characteristics of the organizational design are geared towards facilitating the creation and sharing of knowledge as well as the search for new opportunities.

At the end of the year 2000, the Zeltia Group introduced an incentive system that set out to recognize and reward the initiative and creative skills of all its employees. This firm is explicitly paying for the skill or knowledge that employees acquire during their employment. The direct rationale for such pay policy is clear in this company: A more skillful or better trained employee is more valuable to the organization, and paying for skills, knowledge, or credentials gives employees a motivation to acquire valuable skills and knowledge, and a pay policy of this nature can promote worker retention because it encourages employees to grow in their job.

Linking rewards to observable, verifiable outcomes (rather than behavior) may provide some desirable incentives. Target-based rewards are often a partial solution in settings characterized by exploration actions, as in Zeltia's case. In this vein, the board of directors approved an incentive scheme for all employees with indefinite contracts and a variable annual wage. This scheme provides an opportunity to acquire shares in the company.

Senior managers take decisions that, arguably, have a major impact on a firm's performance, and they have numerous ways in which they can alter their behavior in response to incentives. In this sense, the senior management team also has its own incentive scheme, which is fundamentally based on a variable reward system in the short-term and the combination of a variable and fixed reward system in the long-term. Thus, senior-level managers will be compensated with stock options, and the firm extends this system to line workers through stock-ownership schemes. 
In the literature on incentive mechanisms, compensation is more than just the money paid in the form of wages, salaries, and bonuses. It might include intrinsic or psychological compensation, such as status, independence, power, and so on. In general, the importance given to the non-monetary reward system is very high in this company. Giving its people freedom and autonomy in deciding how and on what to work provides them with intrinsic motivation. Thus, rewards in this company had large non-monetary elements or intrinsic motivation, especially personal autonomy and professional recognition. Furthermore, in this sense, a separate scientific career path was created so technical people could advance without having to move into management.

Instead, close cooperation between the Board of Directors and managers and between managers and employees is used in order to achieve the different organizational objectives. Direct communication between groups was strongly advocated in the organizational transformation process with the idea that multiple approaches to a problem could co-exist, compete, and cross-fertilize one another.

Senior managers at Zeltia highlighted the importance of three factors above and beyond the standard agency problem as the trigger for motivation and as a necessary step for organizational change. These three factors are (a) the recruitment effect; (b) the importance of culture, and (c) the relevance of job definition. For those in charge of human resources at the company, the importance of variable recruitment is very important. If the employee is right for the job and is happy at work, there is less need to include incentive systems designed to increase motivation. Likewise, culture is very important at Zeltia, as it implicitly determines one's attitude to work and one's readiness to take part in assuming risks and accepting commitments and responsibilities. The culture at Zeltia promotes a commitment to work well done, encouraging creativity and the transfer of knowledge within the company. In addition, the company's senior managers indicated that a suitable job definition was an important motivating process over and above that of the agency relationship.

Finally, the company's senior managers explained how important it was that the process of organizational change (from H-form to H-M form) should be well understood by employees - it should be clear to them, and we understand that a useful idea involves the process being perceived as embodying procedural justice.

All the prior arguments highlight the existence of an organizing mode that emphasizes the use of incentive systems in support of exploration.

\subsection{The Case of the Cortefiel Group: brief history}

The origins of this company date back to the end of the $19^{\text {th }}$ century, and today it is one of Spain's oldest and largest groups of textile design, distribution and manufacturing firms. Although the company initially focused solely on the distribution of textile products, a few years later it started to manufacture men's wear. Thus, the firm was a pioneer in developing a vertical integration model which combined design, manufacturing and distribution. In addition, it was also a pioneer in the development of the mass production of garments that is known to suit the new environmental conditions both in Spain and in other countries that manufacture or commercialize different kinds of men's and women's clothing. At present, this textile group includes the Cortefiel brand, founded in 1950; the Springfield and Women's Secret brands, the current leaders in their markets in Spain: men's fashion and lingerie, respectively; the Milano brand, a chain specializing in men's tailoring, clothing, and accessories; the Pedro del Hierro brand, well-known for the elegance of its designs and fine taste in its colors and fabrics; and the Douglas brand, a joint venture entered into with the German company Douglas Holding in the perfume and cosmetics business. 
Furthermore, the Cortefiel Group is a multinational group, with its geographic diversification strategy playing a vital role over the period 1991-2001, mainly from the middle of the decade. The Cortefiel Group is now present in 29 countries around the world, especially in Continental Europe through investment and direct management, and with the Springfield and Women's Secret as a worldwide franchise.

\subsection{Organizational Change in the Cortefiel Group from 1991 to 2001}

The basic mode of organization used for this company over the period 1991-2001 has been the M-form. Nowadays, the Cortefiel Group has a general office and eight semi-autonomous divisions associated with each of its eight brands (Cortefiel, Don Algodón, Milano, Springfield, Women’s Secret, Pedro del Hierro, Douglas and Via Plus), which are structured as functional forms. Each division has its own general manager, marketing manager, sales manager, merchandising team and planning team, several shop managers and agents, as well as sales assistants. Each division or commercial brand is responsible for all functions relating to its customers, design and style, marketing, merchandising, and planning of its product line. On the other hand, strategic decisions are made by the general office, while division managers only make operating or routine decisions related to their respective divisions. The general office carries out the following functions: strategic orientation, legal, technological and computer consultancy, administrative services, financing and control, human resources management, operations management, industrial management and marketing management. This general office is not responsible for allocating the organizational resources across different divisions. This function is the exclusive domain of the senior management team or the Board of Directors. In addition, there is a general manager in each country where this company operates.

However, in recent years, several distinctive features from the N-form can be detected. Specifically, it is interesting to outline how the features of this new form coexist with the features of the M-form.

The main features of the internal network, or $\mathrm{N}$-form, present in this company from the three coordination problems studied are the following: (1) a high level of functional turnover in staff; (2) an increasing autonomy of each division—several years earlier these divisions were basically considered to be departments-over time, coupled with a greater level of decentralization and independence in the decision-making process; (3) an increasing importance given to work teams-the number of persons that integrate each work-team can range from 3 to 20-since one of this company's main goals is to develop highly professional and motivated work teams through internal competition. These work teams have complete freedom for making decisions dealing with the problems that frequently arise. Within this context, horizontal communication between different work teams is very important in order to achieve a streamlined organization.

Therefore, the arguments presented regarding the evolution of coordination mechanisms are consistent with the result of Whittington and Mayer $(1997,2000)$ which shows the appearance of the 'multidivisional network' mode to be a new organizational form in which elements of the traditional form (M-form) coexist with the new form ( $\mathrm{N}$-form). What role have incentive systems played in this process of organizational transformation?

\subsection{The Role of Incentive Systems in Organizational Change Process in Cortefiel}

The Cortefiel Group has designed an incentive system that seeks to highly motivate the different company members. The incentive system implemented by the Cortefiel Group throughout the period 1991-2001 presents 
features that are linked to the exploitation model presented in Table 2. As in the case of the Zeltia Group, the various characteristics of the Cortefiel Group's organizational design go beyond the strictly contractual standpoint, incorporating other elements designed to facilitate focus and execution. The Cortefiel Group's incentive system is based on training and the holding of different meetings or conventions, as well as monetary rewards (sales commissions) for all its employees. The company operates in a more traditional environment in which technical procedures and processes are standardized and, therefore, they can introduce the objective measuring of results upon which to base incentive systems. The essence of exploitation is to achieve maximal performance in delivering within the current strategy. In this vein, Cortefiel focuses all its energy on effective, timely execution. In comparison to the Zeltia Group, and in order to achieve focus and execution, the incentives system is based on quantitative measures of operational performance. Senior managers at Cortefiel said that the better the performance measures of an activity, the less costly it is to provide stronger incentives for the activity in isolation and so induce higher effort. Accordingly, this company focuses on efficiency and measurement combined with present-day quality requirements stemming from the transformation the textile sector has undergone over the past decade. Faced with growing competition from Chinese companies, this company has gone about incorporating high value added specialized technological processes in order to compete with Italian firms, but ones in which, for the time being, Chinese firms do not have the appropriate technology.

The firm pays higher wages to more experienced workers based on their seniority, either in terms of age and tenure in the job or organization (the company has an age-experience premium). The skill level of workers with greater seniority is usually higher and they are more stable workers (lower absenteeism). Seniority- and tenure-based prevails for various reasons, including reducing turnover, increasing the value of an employee throughout their career, union influence and social norms.

Beyond the incentive systems of a contractual nature, senior managers in the Cortefiel Group also revealed the importance of other aspects linked to organizational design in the generic sense, as motivating factors for staff and triggers of organizational change. Amongst these elements in the Cortefiel Group, they pointed to the importance of the following aspects: (a) the allocation of decision authority; (b) the creation of small units geared towards self-management; (c) the establishment of pay systems designed to compensate workers who achieve extraordinary results and (d) culture. The allocation of authority has a powerful impact on incentives. Giving an executive power encourages them to do a better job and to handle more information, exert better control and take better decisions. In turn, according to the company's managers, the creation of smaller units improve the possibilities of measurement and intrinsic motivation. Likewise, they had instituted a system for the payment of commissions that provides extraordinary rewards for those workers who are willing to work harder. Finally, internal sources at the company maintained that culture was an important motivating factor and has considerable importance as an instigator of change. More network elements needed to be included in order to face growing international competition and allow for adjustment towards processes of higher value added. In this sense, there was a need to move from a culture based on high specialization to a culture that catered for training and to the performance of new activities of higher value added. This led to the arrangement of intensive schemes of in-house training.

Therefore, the incentives system implemented by the Cortefiel Group for upholding organizational changed is based on quantitative measures of operational performance. The Cortefiel Group has focused on a policy of efficiency and cost reduction combined with quality that has enabled it to reduce prices and dominate 
the market. This has meant that the incentives it has introduced have involved quantitative measures designed to reinforce control, efficiency and quality simultaneously.

In this company, as in the Zeltia Group, communication with employees is critical in the process of organizational change (from $\mathrm{M}$-form to multidivisional network or $\mathrm{M}-\mathrm{N}$ form), employees should be co-opted into the process as much as possible and procedural justice should be carefully attended.

All the above arguments highlight the existence of an organizing mode that emphasizes the use of incentive systems in support of predictable task performance.

\section{DISCUSSION AND CONCLUSIONS}

This paper has analyzed theoretically and subsequently reported on current longitudinal empirical evidence on the appearance of potential new patterns of organizational behavior. In this sense, we have explored the characteristics related to traditional forms, specifically the M-form and $\mathrm{H}$-form, and to innovative organizational forms, specifically the $\mathrm{N}$-form or internal network, in terms of the evolution of three coordination problems. Furthermore, we have studied the role of their incentive mechanisms in this organizational change process.

A discussion has been made in the prior section regarding the fundamental results of the organizational change experienced in the companies Zeltia and Cortefiel. It has been observed how both companies present different organizational modes, yet both have adopted a similar approach to the incorporation of internal network features. Specifically, Zeltia began with an H-form structure in 1991 and during the period under study it has gradually included fresh combinations of coordination mechanisms designed to incorporate internal network features. The form finally achieved is one that reveals the co-existence of features from traditional forms with features of the new forms giving rise to the holding network form.

In turn, Cortefiel has followed a different organizing mode that focuses more on exploiting, yet in the evolutionary process it has also incorporated elements of new organizational forms. In 1991, it presented the Mform and throughout the decade of the 90's it gradually incorporated internal network elements. The end result is the coexistence of new and traditional forms in the guise of the multidivisional network form.

A special innovation in this process with regard to the literature is that there are prior cases that have shed light on the central role played by incentive systems as a determining factor in organizational change. This leads to the induction of the following original model (see Figure 1).

Taking a further step forward regarding the importance of incentive systems, and based on the James March model, the results have shown us that incentive systems will be a function of the organizing mode in which we find ourselves. We have seen that in the case of Zeltia, the organizing mode involved exploration, whereas for Cortefiel the organizing mode involved exploitation.

The incentives systems implemented by the Zeltia Group as a trigger for organizational change from the $\mathrm{H}$-form to the $\mathrm{H}-\mathrm{N}$ form are designed to facilitate the generation and sharing of knowledge, as well as the search for new opportunities. In turn, the incentives system implemented by the Cortefiel Group for upholding organizational change is based on quantitative measures of operational performance. The Cortefiel Group has focused on a policy of efficiency and cost reduction combined with quality that has enabled it to reduce prices and dominate the market. During the transition from the $\mathrm{M}$-form to the $\mathrm{M}-\mathrm{N}$ form, incentive systems have been 
designed to encourage focus and execution at the same time as they have introduced a series of measures of a psychological and social nature that go beyond measures of a contractual nature.

Figure 1: Coordination mechanisms and incentives systems: traditional forms and new forms

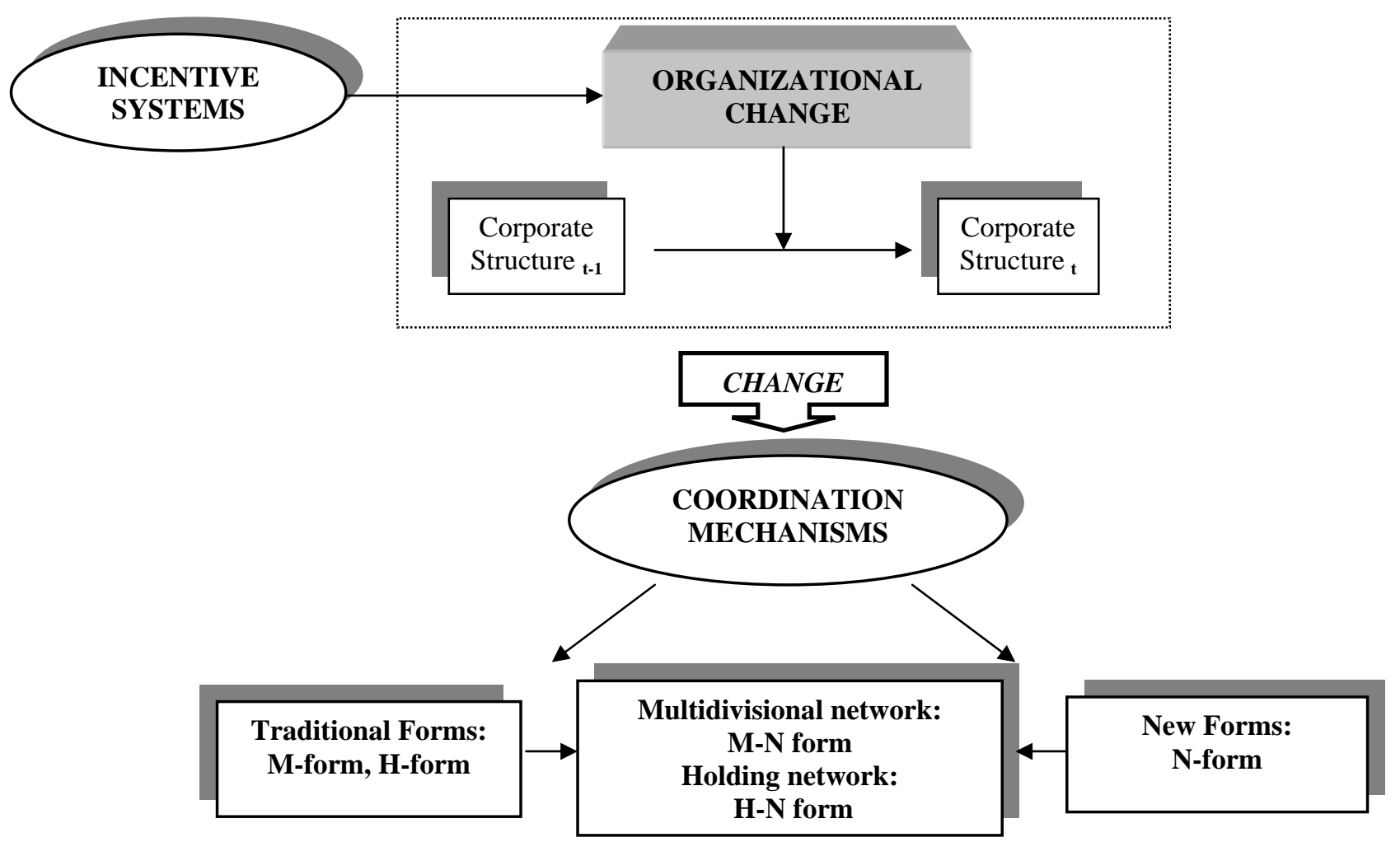

SOURCE: the authors.

An important conclusion of our findings is that incentive systems will not be universally valid as the driving-force of organizational change. In other words, they will be significantly determined by the organizing mode used by the company. Likewise, this process of change will require the introduction of other incentive systems more closely linked to cultural, social and human aspects that exceed the mere contractual sphere. Thus, the incentive systems used by Zeltia are aimed at furthering creativity, cooperation, the search for opportunities and the generation and transfer of knowledge. All this is consistent with the organizing mode geared towards exploring. In turn, beyond the incentives perspective provided by the agency theory, the following system aspects are important in this company (a) recruitment effect; (b) the importance of culture (c) the importance of job description. For its part, the incentive systems at Cortefiel are designed to sharpen the focus on execution and cooperation. In addition, there will also be an important series of systems that exceed the contractual barrier in order to incorporate the social and psychological aspects of individuals. This means that the following are important for this company: (a) the allocation of decision authority, (b) the creation of smaller units, (c) culture.

Our findings make it clear that neither exploration nor exploitation activities are in a pure form, but rather they are present in different proportions. Certain aspects are specific to both mechanisms, such as those aimed at exploration and exploitation in the strict sense, whereas other aspects coexist, such as the need for cooperation and the promotion of intrinsic rewards. 
The findings obtained in the present paper enable the following new propositions to be made:

Proposition 1: The incorporation of network elements in the new organizational forms requires an increase in the weight of incentive systems linked to cultural, social and psychological aspects beyond the contractual approach.

Proposition 2: During the processes of organizational change, companies will have to implement incentive systems that allow for the coexistence of exploration and exploitation actions.

Proposition 3: $\quad$ Companies in more traditional sectors are going to make a more extensive use of incentive systems linked to exploration actions (without forgoing incentive systems that favor exploitation actions).

Proposition 4: $\quad$ Companies in more innovative sectors are going to make a more extensive use of incentive systems linked to exploitation actions (without forgoing incentive systems that favor exploration actions).

All interviews in both case studies indicate the important role of a good incentive scheme to effectively respond to threats stemming from present environmental conditions, and consequently adopt some features of more innovative organizational structures. Creating an effective reward system seems to depend less on finding "the one best way" than on ensuring that the reward system and jobs are designed in tandem, to be consistent and complementary.

We understand there are several important implications for managers. An important issue when considering compensation as a driver of organizational change is how much it wants to rely on direct, shorterterm economic incentives, versus longer-term economic rewards or non-monetary forms of motivation. The second common aspect in both cases is the powerful social and psychological forces beyond the contractual standpoint that motivate people and provoke their reactions to any reward system proposed as driver of organizational change. It will have a profound impact on cognitive perceptions of procedural justice.

Future longitudinal research should focus on explaining the extent to which the adoption of the internal network can be contemplated as either the usual or sporadic mode of organization. Moreover, we firmly believe that a dynamic analysis of the introduction of elements linked to incentive and coordination mechanisms in the characterization of new organizational forms is a thought-provoking issue which researchers are currently beginning to investigate and should continue to explore in the future.

\section{REFERENCES}

Ahuja, M.K. \& Carley, K.M. (1999). Network structure in virtual organizations. Organization Science, 10, 741757.

Baron, J.N. \& Kreps, D.M. (1999). Strategic Human Resources: Frameworks for General Managers. New York: John Wiley.

Bartlett, C.A. \& Ghoshal, S. (1993). Beyond the M-form: Toward a managerial theory of the firm. Strategic Management Journal, 14, 23-46.

Child, J. \& McGrath, R.G. (2001). Organizations unfettered: Organizational form in an information-intensive economy. Academy of Management Journal, 44, 1135-1146.

Dunbar, R. \& Garud, R. (2005). Data indeterminacy: One NASA, two modes. W. H. Starbuck, M. Forjoun, eds. Organization at the limit. Lessons from the Columbia Disaster. Malden, MA: Blackwell Publishing, 202219.

Eisenhardt, K.M. (1989). Building theories from case study research. Academy of Management Review, 14, 532550.

Galan, J.I., Sanchez, M.J. \& Zuñiga-Vicente, J.A. (2005). Strategic and organizational evolution of Spanish firms: Towards a Holding Network form? British Journal of Management, 16, 279-292. 
Galunic, D.C. \& Eisenhardt, K.M. (2001). Architectural innovation and modular corporate forms. Academy of Management Journal, 44, 1229-1249.

Garud, R. \& Van de Ven, A.H. (2001). Strategic change processes. A. M. Pettigrew, H. Thomas, R. Whittington, eds., Handbook of Strategy and Management, London: Sage, 206-231.

Gibbons, R. (1998). Incentives in organizations. Journal of Economic Perspectives, 12, 115-132.

Grant, R.M. (2001). Knowledge and organization. I. Nonaka and H. Takeuchi, eds. Managing Industrial Knowledge: Creation, Transfer and Utilization. London: Sage, 145-169.

Handy, C. (1992). Balancing corporate power: A new federalist paper. Harvard Business Review, 70, 59-72.

Hedlund, G. (1994). A model of knowledge management and the N-form corporation. Strategic Management Journal, 15, 73-90.

Lazear, E.P. (1998). Personnel Economics for Managers. New York: John Wiley.

March, J. (1991). Exploration and exploitation in organizational learning. Organization Science, 2, 71-87.

March, J. G., Sproull, L. S. \& Tamuz, M. (1991). Learning from samples of one of fewer. Organization Science, 2, 1-13.

Miles, R.E., Snow, C.C., Mathews, J.A., Miles, G. \& Coleman, H.J. (1997). Organizing in the knowledge age: Anticipating the cellular form. Academy of Management Executive, 11, 7-24.

Milgrom, P. \& Roberts, J. (1992). Economics, Organization and Management. Englewood Cliffs NJ: Prentice Hall.

Pettigrew, A., Woodman, R.W. \& Cameron, K.S. (2001). Studying organizational change and development: Challenges for future research. Academy of Management Journal, 44, 697-713.

Pettigrew, A.M. (1990). Longitudinal field research on change: Theory and practice. Organization Science, 1, 267-292.

Pettigrew, A.M. (1992). The character and significance of strategy process research. Strategic Management Journal, 13, 5-16.

Pettigrew, A.M. \& Fenton, E.M. (2000). TheInnovating Organization. London: Sage.

Roberts, J. (2004). The Modern Firm. Organizational Design for Performance and Growth. New York: Oxford University Press.

Ruigrok, W., Pettigrew, A., Peck, S. \& Whittington, R. (1999). Corporate restructuring and new forms of organizing: Evidence from Europe. Management International Review, 39, 41-64.

Saloner, G., Shepard, A. \& Podolny, J. (2001). Strategic Management. New York: John Wiley \& Sons.

Sanchez, R. \& Mahoney, J.T. (1996). Modularity, flexibility, and knowledge management in product and organization design. Strategic Management Journal, 17, 63-76.

Teece, D. (2001). Strategies for managing knowledge assets. I. Nonaka, and H.Takeuchi, eds. Managing Industrial Knowledge. London: Sage, 125-144.

Van de Ven, A.H. \& Poole, M.S. (1995). Explaining development and change in organizations. Academy of Management Review, 20, 510-540.

Van Wijk, R.A. \& van den Bosch, F. A. J. (2000). The emergence and development of internal networks and their impact on knowledge flows: The case of Rabobank group. A. M. Pettigrew, E. F. Fenton, eds. The Innovating Organization. London: Sage, 144-177.

Whittington, R., Pettigrew, A., Peck, S., Fenton, E. \& Conyon, M. (1999). Change and complementarities in the new competitive landscape: A European panel study, 1992-1996. Organization Science, 10, 583-600.

Williamson, O. E. (1975). Markets and hierarchies: Analysis and antitrust implications. New York: Free Press.

Williamson, O. E. \& Bhargava, N. (1972). Assessing and classifying the internal structure and control apparatus of the modern corporation. R. Marris and A. Wood, eds. The Corporate Economy. New York: Free Press.

Yin, R.K. (1994). Case Study Research: Design and Methods. London: Sage.

Zajac, E.J. \& Westphal, J.D. (2002). Intraorganizational economics. J. A. Baum, ed. Companion to Organizations. Malden: Blackwell Publishers Inc, 233-255. 